\title{
The Influence of Copper Loading and Surface Coverage on the Reactivity of Granular Iron Toward 1,1,1-Trichloroethane
}

\author{
Stephen J. Bransfield, ${ }^{1}$ David M. Cwiertny, ${ }^{2}$ A. Lynn Roberts, ${ }^{2}$ D. Howard Fairbrother,,${ }^{1}$ * \\ ${ }^{1}$ Department of Chemistry, ${ }^{2}$ Department of Geography and Environmental Engineering \\ ${ }^{3}$ Department of Materials Science and Engineering, \\ Johns Hopkins University, 3400 N. Charles St., Baltimore, MD 21218
}

\section{Supporting Information}

\section{Pages}

2 Figures

Supporting Information describes the reagents used in this investigation, provides a more detailed description of the protocol used for preparing $\mathrm{Cu} / \mathrm{Fe}$ bimetallic reductants, and details the methods employed for reductant characterization using Scanning Electron Microscopy Energy Dispersive X-ray Spectroscopy (SEM-EDS) and X-ray Photoelectron Spectroscopy (XPS). Also provided are results from XPS analysis of $\mathrm{Cu} / \mathrm{Fe}$ reductants (Figure $\mathrm{S}-1$ ), and results

(Figure S-2) pertaining to changes in 1,1,1-TCA reduction rate and product distribution as a function of $\mathrm{Cu}$ loading. 


\section{Reagents:}

In our study of $\mathrm{Cu} / \mathrm{Fe}$ bimetallic reductants, the following chemicals were used as received: 1,1,1-TCA (99.5\%; Aldrich); 1,1-DCA (99\%; TCI America); 2-butyne (99\%; Aldrich); ethane, ethylene and cis-2-butene (Scott Specialty Gases); $\mathrm{CuCl}_{2} \cdot 2 \mathrm{H}_{2} \mathrm{O}$ and $\mathrm{CuCl}$ (93.9\%) (Fisher); tris(hydroxymethyl)aminomethane and tris(hydroxymethyl)aminomethane hydrochloride (reagent grade; Sigma). Spiking solutions $(0.32 \mathrm{M})$ of 1,1,1-TCA and 1,1-DCA were prepared in deoxygenated methanol. Copper powder (laboratory grade; Fisher) was used to examine the reactivity of copper in the absence of iron. 


\section{Protocol for Bimetallic Particle Preparation}

Bimetallic reductants were prepared in an anaerobic chamber $\left(95 \% \mathrm{~N}_{2} / 5 \% \mathrm{H}_{2}\right.$ atmosphere) using electrolytic iron powder (100 mesh, 95\%; Fisher) as the base metal. Iron particles were pretreated by acid-washing with $1 \mathrm{M} \mathrm{HCl}$ (Fisher) (approximately $20 \mathrm{~mL} \mathrm{HCl} / \mathrm{g}$ of iron) for 10 minutes. The acid-washed metal samples were then rinsed 3 times with deoxygenated $\left(\mathrm{N}_{2}\right.$ sparged), deionized water (Milli-Q Plus UV, Millipore).

Displacement plating was performed by adding $25 \mathrm{~mL}$ of either $\mathrm{Cu}^{\mathrm{I}}$ or $\mathrm{Cu}^{\mathrm{II}}$ chloride solution to $2 \mathrm{~g}$ of acid-washed iron. To vary the amount of copper deposited, a range of $\mathrm{CuCl}$ and $\mathrm{CuCl}_{2}$ concentrations ( $40 \mu \mathrm{M}$ to $0.05 \mathrm{M}$ ) was employed. Based upon reported stability constants for $\mathrm{Cu}(\mathrm{OH})_{2}$ (s) formation (1), our plating solutions are not expected to exceed the solubility limit of $\mathrm{Cu}^{2+}$. After adding the copper solution to the granular iron, the slurry was vigorously mixed by hand for 1 minute, followed by a decant step in which the metal reductant was separated from the solution. Plated samples were rinsed three times with deoxygenated, deionized water, once with deoxygenated acetone, and were then dried under $\mathrm{N}_{2}$ at $100^{\circ} \mathrm{C}$ for $30 \mathrm{~min}$. 


\section{Particle Characterization:}

Scanning Electron Microscopy Energy Dispersive X-ray Spectroscopy (SEM-EDS): Crosssectional SEM-EDS analysis of $\mathrm{Cu} / \mathrm{Fe}$ were obtained after the grains were embedded in epoxy, mechanically ground, polished to a $0.3 \mu \mathrm{m}$ finish and then coated with $50 \AA$ of carbon to reduce charging. A JEOL 8600 Superprobe operating at $25 \mathrm{kV}$ and a beam current of $60 \mathrm{nA}$ was used to image the $\mathrm{Cu} K \alpha$ line. Backscattered secondary electron maps were collected at a resolution of $2048 \times$ 1600. X-rays were collected using an EDAX light-element energy dispersive spectrometer (EDS), and data were processed by the GENESIS spectral imaging software (EDAX). Several $256 \times 200$ pixel maps were generated using a dwell time of 1 second. At each

pixel, an entire EDS spectrum was generated and stored for later processing. Images related to X-ray intensities were extracted by fitting Gaussian curves to each peak within the spectrum. 
X-ray Photoelectron Spectroscopy (XPS): XPS was used to probe the oxidation state of $\mathrm{Cu}$ on the $\mathrm{Cu} / \mathrm{Fe}$ reductants. Figure S-1a shows the $\mathrm{Cu}\left(\mathrm{L}_{3} \mathrm{M}_{4,5} \mathrm{M}_{4,5}\right)$ Auger region of the XP spectra from a $\mathrm{Cu} / \mathrm{Fe}$ bimetallic reductant following the plating of granular iron with $12 \mu$ moles $\mathrm{Cu} / \mathrm{g} \mathrm{Fe}$ from a $\mathrm{CuCl}_{2}$ aqueous salt solution. Auger peaks for $\mathrm{Cu}$ were observed at energies of 335 and $337 \mathrm{eV}$; the peak at $335 \mathrm{eV}$ is indicative of the presence of $\mathrm{Cu}^{0}$, while the peak at $337 \mathrm{eV}$ could reflect either $\mathrm{Cu}^{\mathrm{I}}$ or $\mathrm{Cu}^{\mathrm{II}}$ on the particle surface. Examination of the $\mathrm{Cu}(2 \mathrm{p})$ XP region between 975-925 eV (data not shown) did not reveal any peaks characteristic of $\mathrm{Cu}^{\mathrm{II}}$, indicating that the copper at the surface was present in both $\mathrm{Cu}^{0}$ and $\mathrm{Cu}^{\mathrm{I}}$ oxidation states.

$\mathrm{Ar}^{+}$ion sputtering was used in conjunction with XPS in order to assess whether the $\mathrm{Cu}^{\mathrm{I}}$ form persists at depths below the first few monolayers. XP spectra obtained after etching through a depth less than 1 monolayer (Figure S-1b) revealed a significant decrease in the $\mathrm{Cu}^{\mathrm{I}}$ peak intensity at $337 \mathrm{eV}$, while the $\mathrm{Cu}^{0}$ peak at $335 \mathrm{eV}$ became dominant. After prolonged $\mathrm{Ar}^{+}$ sputtering $(\sim 40 \AA)$, the $\mathrm{Cu}(2 \mathrm{p})$ and $\mathrm{Cu}$ Auger regions were consistent with the presence of metallic copper alone. The disappearance of $\mathrm{Cu}^{\mathrm{I}}$ from the surface and the corresponding increase in the $\mathrm{Cu}^{0}$ peak intensity suggest that copper is deposited on the iron surface as metallic $\mathrm{Cu}$. We hypothesize that the thin cuprous oxide layer on the $\mathrm{Cu} / \mathrm{Fe}$ bimetallic surface reflects trace oxidation of the surface by atmospheric $\mathrm{O}_{2}$ during sample transfer into the XPS chamber. This is supported by the sporadic occurrence of $\mathrm{Cu}^{\mathrm{I}}$ on these samples, as some $\mathrm{Cu} / \mathrm{Fe}$ reductants were generated in which no $\mathrm{Cu}^{\mathrm{I}}$ peaks could be detected by XPS.

More limited XPS analyses of $\mathrm{Cu} / \mathrm{Fe}$ reductants generated via immersion plating with $\mathrm{CuCl}$ yielded results similar to those obtained from $\mathrm{CuCl}_{2}$ solutions. This indicates that the oxidation state of the copper ultimately deposited is not sensitive to the oxidation state of the copper salt present during displacement plating. 
Figure S-1

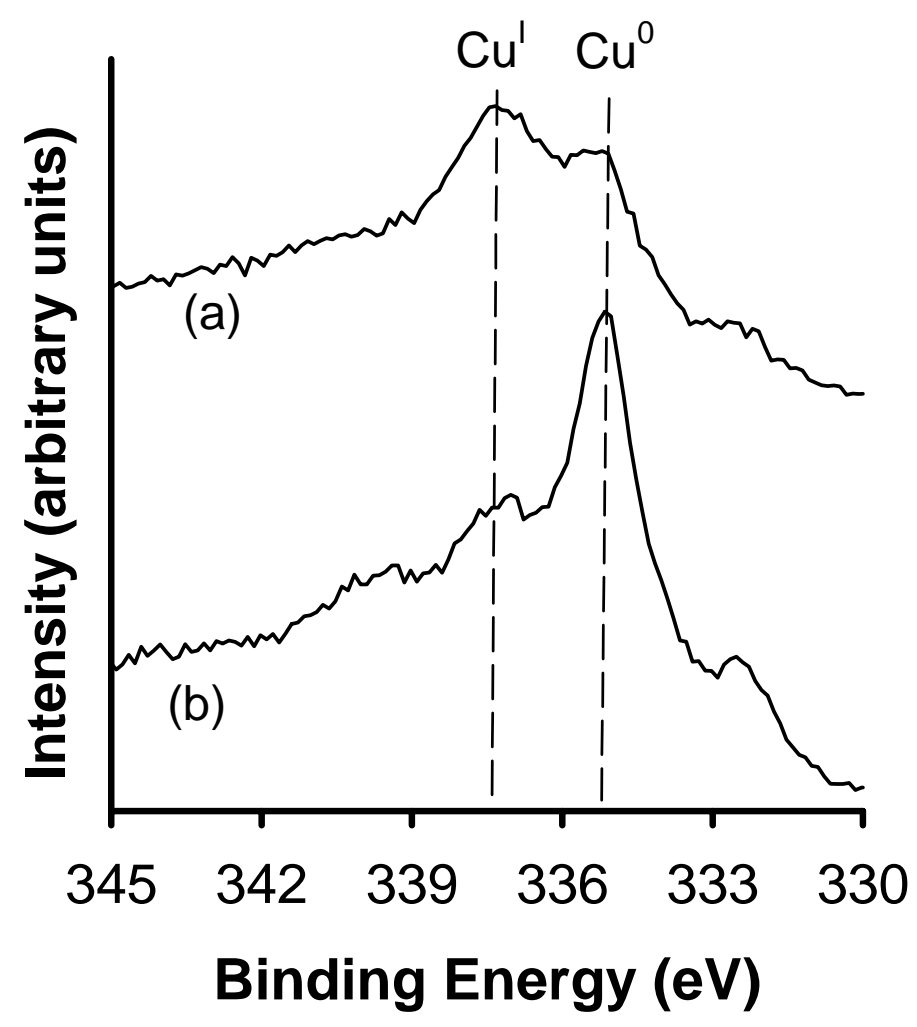

Figure S-1: X-ray photoelectron spectra of the $\mathrm{Cu}\left(\mathrm{L}_{3} \mathrm{M}_{4,5} \mathrm{M}_{4,5}\right)$ AES region both (a) before and (b) after sputtering with $\mathrm{Ar}^{+}$through $<1$ monolayer. Spectra are of a granular iron sample plated with $12 \mu$ moles $\mathrm{Cu} / \mathrm{g} \mathrm{Fe}$ from a $\mathrm{CuCl}_{2}$ aqueous salt solution. The dashed lines denote characteristic binding energies of $\mathrm{Cu}^{\mathrm{I}}$ and $\mathrm{Cu}^{0}$. 


\section{Effect of Cu Loading on Particle Reactivity toward 1,1,1-TCA:}

The effect of increasing $\mathrm{Cu}$ loading on the rate of 1,1,1-TCA reduction was examined with batch studies. Time courses for 1,1,1-TCA reduction (examples of which are provided in Figure S-2a) showed good adherence to exponential decay, as demonstrated by the agreement between the model fits (dashed lines in Figure S-2a) and experimental data. Over the range of copper loadings investigated, the addition of copper to the iron surface produced more than a five-fold increase in the magnitude of pseudo-first-order rate constants ( $k_{\text {obs }}$ values) compared to unamended granular iron.

Increasing the mass of deposited copper produced a systematic shift in 1,1,1-TCA product partitioning to favor fully dehalogenated species. The three major products of 1,1,1-TCA reductive dehalogenation in iron and $\mathrm{Cu} / \mathrm{Fe}$ systems are 1,1-DCA, ethane and ethylene, which together constitute approximately $90-95 \%$ of the total products observed. Figure S-2b shows the percent contribution of ethane and ethylene production to the total loss of 1,1,1-TCA from solution. This contribution was calculated at a time corresponding to one half-life for the three time courses shown in Figure S-2a; relative product yields did not change thereafter. These data indicate that for iron plated with $6 \mu$ moles $\mathrm{Cu} / \mathrm{g} \mathrm{Fe}$ from a $\mathrm{CuCl}_{2}$ aqueous salt solution, approximately $25 \%$ of $1,1,1-\mathrm{TCA}$ is converted to ethane and ethylene. In contrast, for iron particles plated with $125 \mu$ moles $\mathrm{Cu} / \mathrm{g} \mathrm{Fe}$ from a $\mathrm{CuCl}_{2}$ aqueous salt solution, the combined yield of ethane and ethylene was roughly $50 \%$. 

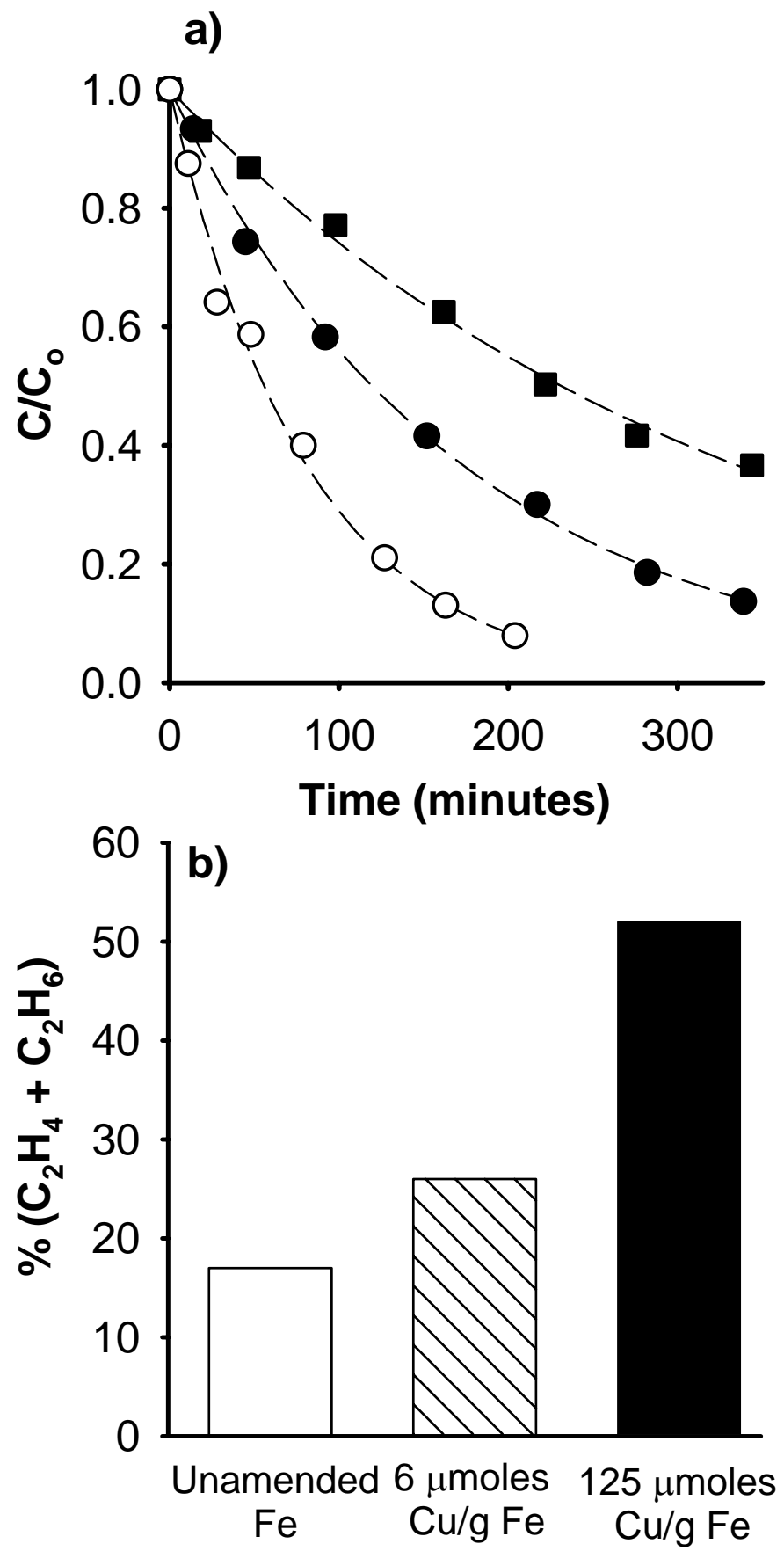

Figure S-2: a) Time courses illustrating the loss of 1,1,1-TCA from solution as a result of reduction by $(\bullet)$ unplated granular iron $\left(k_{\text {obs }}\right.$ of $\left.3.18( \pm 0.216) \times 10^{-3} \mathrm{~min}^{-1}\right) ;(\bullet)$ iron plated with 6 $\mu$ moles $\mathrm{Cu} / \mathrm{g} \mathrm{Fe}$, yielding a $k_{\text {obs }}$ value of $5.84( \pm 0.246) \times 10^{-3} \mathrm{~min}^{-1}$; and (o) iron plated with 125 $\mu$ moles $\mathrm{Cu} / \mathrm{g} \mathrm{Fe}, 82 \% \mathrm{Cu})$ yielding a $k_{\mathrm{obs}}$ value of $1.24( \pm 0.0671) \times 10^{-2} \mathrm{~min}^{-1}$. Dashed lines reflect exponential decay fits to 1,1,1-TCA data. b) The fractional contribution of ethane and ethylene produced during the reduction of 1,1,1-TCA. The data used to compile this figure were taken from the time courses in (a) at the first half-life of the reaction. Carbon mass balances for these experiments were on the order of $80-90 \%$. 


\section{References:}

(1) Smith, R. M.; Martell, A. E. Critical Stability Constants: Inorganic Complexes; Plenum: New York, 1976; Vol. 4. 